\title{
Clinical benefit of immune checkpoint inhibitors approved by US Food and Drug Administration
}

Fei Liang ${ }^{1,2}$, Sheng Zhang ${ }^{1 *}$, Qin Wang ${ }^{3^{*}}$ and Wenfeng $\mathrm{Li}^{4^{*}}$

\begin{abstract}
Background: We describe the clinical benefit of immune checkpoint inhibitors using the European Society for Medical Oncology Magnitude of Clinical Benefit Scale (ESMO-MCBS) and ASCO VF.

Methods: We identify all approved indications of immune checkpoint inhibitors based on RCTs between January 1 , 2011 and September 30, 2018 by FDA. Information including medians and HR of OS (PFS or DFS) and 95\% Cl, grade 3 or 4 toxicities in each arm, QOL data, survival probability at fixed time were extracted.

Results: Immune checkpoint inhibitors were approved for 18 indications based on RCTs. All the indications meet the ESMO-MCBS 1.1 threshold for meaningful benefit. By the updated ASCO-VF, the median Net Health Benefit (NHB) of these agents was 55.3 (range 17.4-77.1). Two third of the indication gained the bonus points for durable survival benefits by updated ASCO VF. When updated results were incorporated in the assessment, clinical benefit of most approved immune checkpoint inhibitors increased with a median improvement of NHB of 10 (range 2-20).

Conclusions: Approved immune checkpoint inhibitors provided clinical meaningful benefit by ESMO-MCBS 1.1, and most of these agents reach the threshold for bonus points for durable survival in the updated ASCO VF.

Keywords: Randomized trials, Clinical benefits, Immune checkpoint inhibitors, Cancer, Food and drug administration agency
\end{abstract}

\section{Background}

Knowledge of the potential benefits and risks associated with the use of anticancer therapies is fundamental for making treatment-related recommendations and decisions. Two important oncology societies have recently taken a step forward to quantize the clinical benefit. The American Society of Clinical Oncology (ASCO) Value Framework (ASCO-VF) [1], which was updated in 2016

\footnotetext{
*Correspondence: wozhangsheng@hotmail.com; 2817403929@qq.com; li_wenfeng@126.com

'Medical Oncology, Shanghai Cancer Center, Fudan University, 270 Dongan Road, Shanghai 200032, China

${ }^{3}$ Shanghai University of Engineering Science, Shanghai, China

${ }^{4}$ Department of Medical oncology, the affiliated hospital of Qingdao University, Qingdao, China

Full list of author information is available at the end of the article
}

[2], and the European Society for Medical Oncology developed its Magnitude of Clinical Benefit Scale (ESMO-MCBS) for drugs indicated in the treatment of solid cancer [3], which also updated in 2017 [4]. They have been used to grade US Food and Drug Administration (FDA)-approved new drugs for treating advanced solid cancers [5-7]. In the study by Vivot and colleagues, they found that Many recently FDA-approved new cancer drugs did not have high clinical benefit as measured by ASCO-VF and ESMO-MCBS.

The growing wave of progress using cancer immunotherapy, which has extended and improved the lives of patients, many of whom had few other effective treatment options has yielded high expectations from all stakeholders. However, there are also concerns about the value

C C The Author(s). 2020 Open Access This article is licensed under a Creative Commons Attribution 4.0 International License, which permits use, sharing, adaptation, distribution and reproduction in any medium or format, as long as you give appropriate credit to the original author(s) and the source, provide a link to the Creative Commons licence, and indicate if changes were made. The images or other third party material in this article are included in the article's Creative Commons licence, unless indicated otherwise in a credit line to the material. If material is not included in the article's Creative Commons licence and your intended use is not permitted by statutory regulation or exceeds the permitted use, you will need to obtain permission directly from the copyright holder. To view a copy of this licence, visit http://creativecommons.org/licenses/by/4.0/ The Creative Commons Public Domain Dedication waiver (http://creativecommons.org/publicdomain/zero/1.0/) applies to the data made available in this article, unless otherwise stated in a credit line to the data. 
of check point inhibitors. Many immune checkpoint inhibitors were approved based on single-arm studies, only recently more RCTs were finished and reported.

Patient-reported outcomes (PROs), such as symptoms, quality of life (QOL), and patient-perceived health status supplement clinical data and are now more important during decision-making in oncology because they provide a holistic understanding of patient experience and treatment effectiveness $[8,9]$. Both ESMO-MCBS and ASCO VF incorporated QOL into the determination of the value of a treatment. ASCO VF awarded bonus points for treatment with a statistically significant improvement in cancer-related symptoms. However, PROs usually were not reported in the primary report or approval documents, but subsequently reported as separate articles.

In this study, we aimed to describe the clinical benefit of checkpoint inhibitors that were recently approved by the FDA based on RCTs using ESMO-MCBS and ASCO $\mathrm{VF}$, and whether these agents reach defined thresholds of long-term benefit in the two value frameworks. We also compare the values based on primary reports with those assessed based on updated reports including longterm survival reports and/or QOL reports.

\section{Methods}

\section{Data sources}

We identify all approved indications of immune checkpoint inhibitors (Ipilimumab, Nivolumab, pembrolizumab, Atezolizumab, Avelumab, and Durvalumab, Cemiplimab) between January 1, 2011 and September 30, 2018 by searching FDA website [10]. Only indications approved based on RCTs were included and those approved based on single arm trials were excluded. Indications that were granted accelerated approval based on single arm trials but subsequently obtained regular approval with positive confirmatory RCTs were included. We included drugs used both in the metastatic setting and adjuvant setting of treatment of solid tumors.

\section{Data extraction}

Information including medians and HR of OS (PFS or DFS) and 95\% CI, grade 3 or 4 toxicities in each arm, QOL data, survival probability at fixed or specified time were extracted from the reports of pivotal clinical trials supporting the FDA approval and FDA documents (drug labels and review summary retrieved from Drugs@fda website [10]). Survival probability at fixed or specified time was extracted directly from Kaplan-Meier curves using digital software (DigitizeIt). Baseline characteristics such as drug name, indication, trial name, sample size, primary outcome, tumor type, year of approval were also collected. When statistically significant results were reported for more than experimental arms, then each arm was evaluated separately and assigned a separate grade.

\section{ESMO-MCBS and the ASCO-VF}

ASCO-VF and ESMO-MCBS both quantify treatment benefit in a survival endpoint. ESMO-MCBS grade was assigned based on the lower limit of the 95\% confidence interval of the hazard ratio (HR), and in conjunction with the minimum absolute gain differences in median survival or by the increase in survival at a fixed time, and further adjusted on QOL, toxicity and long term plateau of survival curve. ESMO-MCBS grades, in the non-curative setting, range from 1 to 5 , with grades 4 and 5 representing meaningful clinical benefit, in the curative setting, range from $A$ to $C$, with $A$ and $B$ representing meaningful clinical benefit. ASCO-VF score was assigned primarily on the point estimate of the HR with adjustment on toxicity and bonus points including tail of the curve, palliation, QOL and treatment-free interval. ASCO-VF score is continuous with a higher score representing a better score, and no cut-off value was provided to define clinical benefit. Both value frameworks incorporated amendments to introduce tail-of-the curve credits for progression-free survival and overall survival. For ESMO-MCBS, credit is given for a $10 \%$ or greater absolute gain at prognostically weighted specified time points in the true tail of the curve. Grading based on "long term" survival points differs depending on a PFS or OS endpoint (i.e., for PFS, this is an upgrade, while, for OS, this is an additional grading using the curative framework, e.g., 4/A). None of the trials actually meet this OS upgrade given the length of time required for the data to mature. ASCO-VF awarded 20 points of tailof-the-curve bonus points if, at twice the median survival time (or DFS) in the control arm, there was an improvement of at least $50 \%$ in survival provided the survival in the control group was at least $20 \%$ and award 16 points $(0.8 \times 20)$ if the improvement is in PFS. ASCO-VF further awarded treatment with a statistically significant improvement in cancer-related symptoms (10 points) or improvement in treatment-free interval (10 points).

Two review authors (F.L. and S.Z.) independently scored each indication using ESMO-MCBS and the ASCO-VF with discrepancies resolved by a third investigator. We used the $\mathrm{k}$ coefficient to determine degree of agreement between reviewers. For trials with two or more immunotherapy arms, we scored each arm separately, but only the arm with higher score was used to represent the value of the specific indication in all analysis.

\section{Updated value score}

Value of approved drugs may change as long-term follow-up data or QOL data (which is usually not available or reported when initially approved) become available. Particularly, drugs that failed to qualify the tail of 
the curve bonus due to limited follow-up time can show long term plateauing of survival with longer follow-up time.

We searched latest drug label or PubMed to identify if updated reports of survival, toxicity or quality of life data and assigned updated score for these indications. When multiple reports of updated reports of survival were published, the most up-to-date one was used.

\section{Results}

Eighteen indications for 5 immune checkpoint inhibitors were approved by the FDA for metastatic solid tumors based on RCTs from March 2011 to September 2018 (Table 1). Two approvals were for adjuvant therapy and 16 for non-curative therapy. The approvals were for melanoma (7 indications), NSCLC (7 indications), head and neck cancer (1indication), urothelial carcinoma (1indication) and renal cell carcinoma (1indication). Median sample size of pivotal RCTs was 694 (range 272-1034) (Table 1).

\section{Clinical benefit of immune checkpoint inhibitors}

Eighteen pivotal RCTs were included for the value assessment, with 5 trials had two experimental arms. By the ESMO-MCBS 1.1, for the 16 trials in the noncurative setting, 8 trials were grade five (the highest), and 8 trials grade four. For the two trials in the adjuvant setting, both were grade A. Thus, all trials met the ESMO-MCBS meaningful benefit threshold. Three trials met the ESMO-MCBS long term benefit criteria, all with the primary endpoint of PFS. Twelve of trials meet the criteria of improved toxicity (less grade 3-4 toxicities impacting on daily well-being) and only one trial was considered as increased toxic death.

By the ASCO-VF, the median Net Health Benefit (NHB) of drugs was 55.3 (range 17.4-77.1). The median treatment effect score was 34.4 (range 25-58) and the median toxicity score was 3.8 (range -7.6 to 11.3 ), with 13 trials have positive toxicity score and 5 trials with negative toxicity score (Table 2). 12(66.7\%) trials gained the long tail bonus points in the ASCO framework. Bonus points for a tail on OS curves were granted for 6

Table 1 Characteristics of immune-checkpoint inhibitors approved by US FDA

\begin{tabular}{|c|c|c|c|c|c|}
\hline Approved drug & Indications & Pivotal Trial & $\begin{array}{l}\text { Primary } \\
\text { endpoint }\end{array}$ & $\begin{array}{l}\text { Sample } \\
\text { size }\end{array}$ & $\begin{array}{l}\text { Year of } \\
\text { approval }\end{array}$ \\
\hline $\begin{array}{l}\text { Pembrolizumab plus } \\
\text { chemotherapy }\end{array}$ & First-line therapy of metastatic non-squamous NSCLC & KEYNOTE-189 & OS and PFS & 616 & 2018 \\
\hline Nivolumab plus ipilimumab & $\begin{array}{l}\text { First-line therapy of intermediate or poor risk advanced renal } \\
\text { cell carcinoma }\end{array}$ & CHECKMATE-214 & OS, ORR and PFS & 847 & 2018 \\
\hline Durvalumab & $\begin{array}{l}\text { Consolidation therapy for stage III NSCLC who did not have } \\
\text { disease progression after two or more cycles of platinum-based } \\
\text { chemoradiotherapy }\end{array}$ & PACIFIC & PFS and OS & 713 & 2018 \\
\hline Atezolizumab & Second line therapy of NSCLC & OAK & OS & 850 & 2016 \\
\hline Pembrolizumab & Second line therapy foradvanced urothelial carcinoma & KEYNOTE-45 & PFS and OS & 542 & 2017 \\
\hline Pembrolizumab & $\begin{array}{l}\text { First-line NSCLC with tumors express PD-L1 > 50\% as } \\
\text { determined by an FDA-approved test }\end{array}$ & KEYNOTE-24 & PFS & 305 & 2017 \\
\hline Pembrolizumab & $\begin{array}{l}\text { Second line therapy of metastatic NSCLC whose tumors } \\
\text { express PD-L1 }\end{array}$ & KEYNOTE-010 & PFS and OS & 1034 & 2016 \\
\hline Pembrolizumab & First-line therapy of melanoma & KEYNOTE-006 & PFS and OS & 834 & 2015 \\
\hline Nivolumab & Adjuvant therapy of melanoma & CHECKMATE-238 & RFS & 906 & 2017 \\
\hline Nivolumab & $\begin{array}{l}\text { Second line therapy of squamous-cell carcinoma of the head } \\
\text { and neck }\end{array}$ & CHECKMATE-141 & OS & 361 & 2016 \\
\hline Nivolumab & Second line therapy of renal cell carcinoma & CHECKMATE-025 & OS & 821 & 2015 \\
\hline Nivolumab & Second line therapy of advanced squamous-cell NSCLC & CHECKMATE-017 & OS & 272 & 2015 \\
\hline Nivolumab & Second line therapy of advanced nonsquamous NSCLC & CHECKMATE-057 & OS & 582 & 2015 \\
\hline Nivolumab & $\begin{array}{l}\text { First line therapy of BRAF wild-type unresectable or metastatic } \\
\text { melanoma }\end{array}$ & CHECKMATE-066 & OS & 418 & 2015 \\
\hline $\begin{array}{l}\text { Nivolumab with or } \\
\text { without ipilimumab }\end{array}$ & First line therapy of unresectable or metastatic melanoma & CHECKMATE-067 & PFS and OS & 945 & 2015 \\
\hline Pembrolizumab & Second line therapy of unresectable or metastatic melanoma & KEYNOTE-002 & PFS & 540 & 2015 \\
\hline Ipilimumab & Adjuvant therapy of melanoma & EORTC-18071 & RFS & 951 & 2015 \\
\hline Ipilimumab & Second line therapy of unresectable or metastatic melanoma & MDX010-20 & OS & 676 & 2011 \\
\hline
\end{tabular}




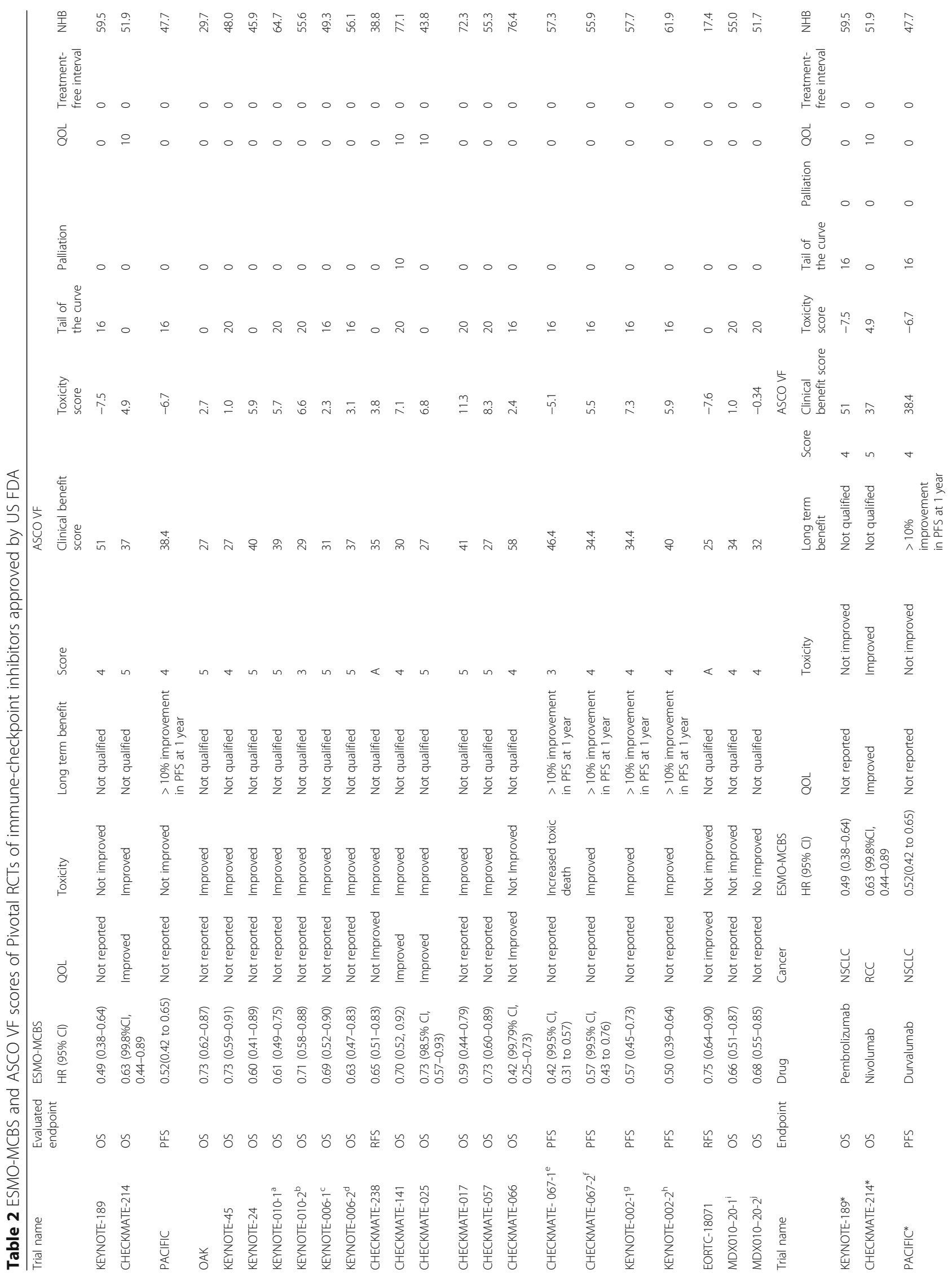




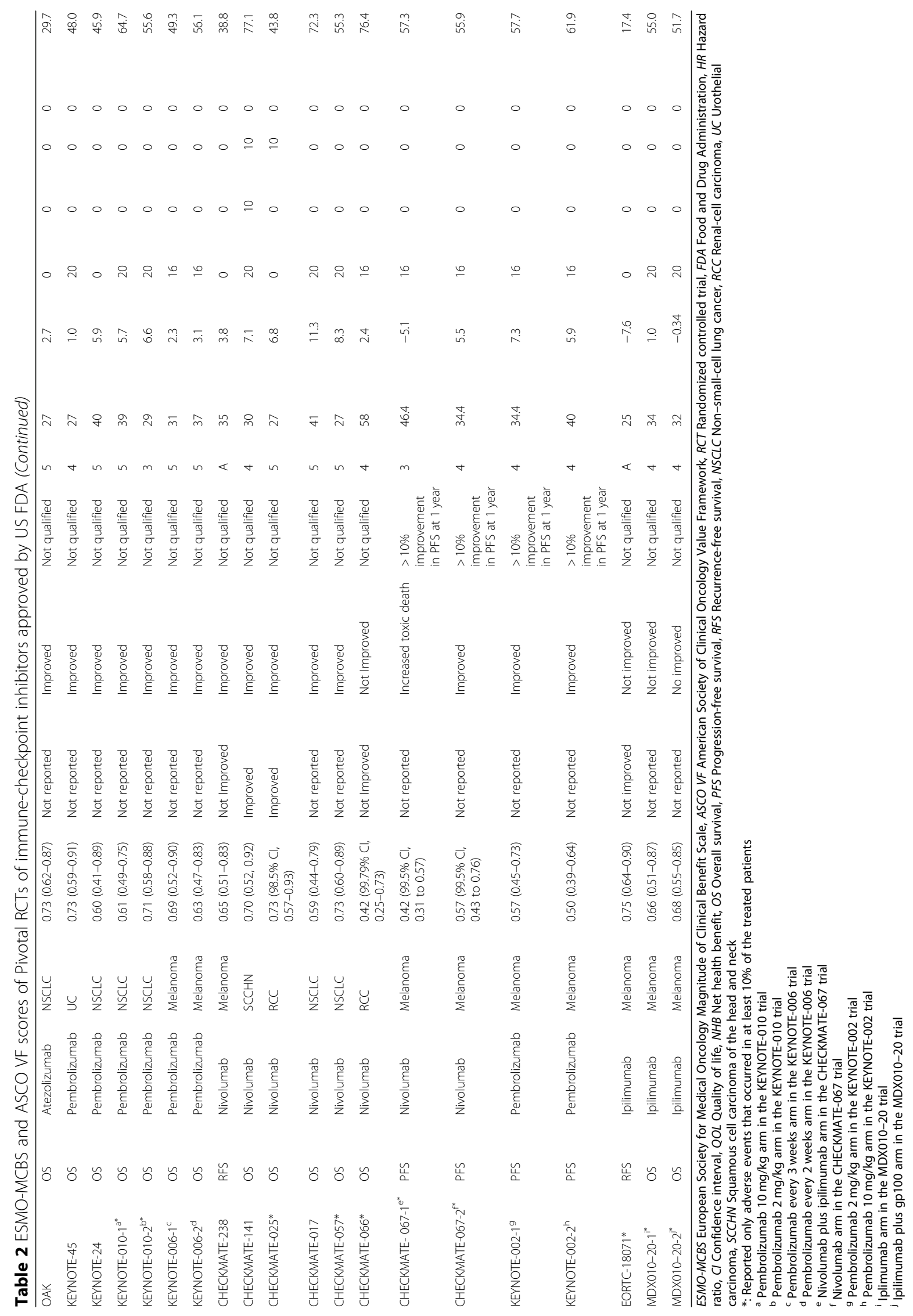


trials (33.3\%) and for PFS curves for 6 trials (33.3\%) (Fig. 1). For the remaining 6 trials not qualified for the tail of the curve bonus, survival proportions with standard regimen at $2 \mathrm{X}$ the median OS (or PFS or DFS) were not available for three trials due to limited follow-up time and three trials did not achieved the required 50\% improvement in patients alive in the test regimen compared with the standard (Fig. 1). Bonus for palliation symptoms was granted for 1 trial (5.5\%); and for improvement in QoL for 3 trials (16.7\%). No drugs received bonus points for treatment-free interval (Table 2).

For trials with ESMO-MCBS grade of 4, the median NHB was 49.3 (range 17.4-72.3), while for those with ESMO-MCBS grade of 5 or A, the median NHB was 56.8 (range $47.7-71.1$ ).

\section{Updated clinical benefit}

Fourteen trials reported updated survival results or toxicity data or quality of life data. ESMO-MCBS grades

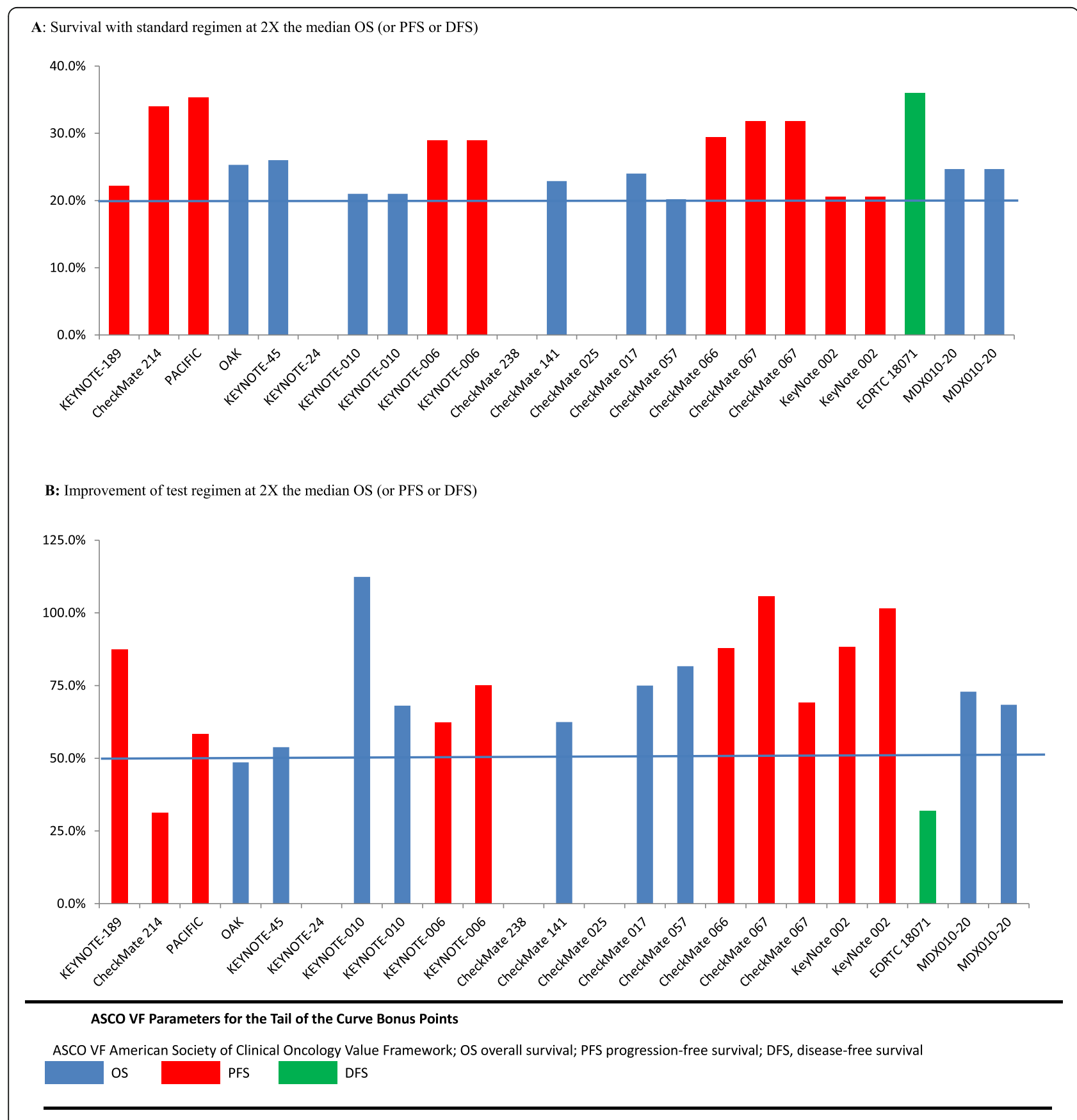

Fig. 1 ASCO VF Parameters for the Tail of the Curve Bonus Points 
were changed for two trials, both of which increased from 4 to 5 (Table 3). The ESMO-MCBS grade of CHECKMATE-066 [11, 12], which support the approval of nivolumab as first line therapy of BRAF wild-type unresectable or metastatic melanoma increased from 4 to 5 due to improved QOL, which were not available in the primary report [11] and approval documents. Nivolumab as second line therapy of squamous-cell carcinoma of the head and neck obtained ESMO-MCBS grade of 4 based on lower limit of HR of OS $<0.65$ and gain of 2.4 months (preliminary score of 3 ) and improved QOL and less grade 3-4 toxicities reported in the primary report of CHECKMATE-141 trial [13]. This indication now obtained a score of 5 due to increased preliminary score with increase in 2 year survival of $>10 \%$ reported in the 2-year long-term survival update report [14]. Two trials (PACIFIC and CHECKMATE-067) no longer met the ESMO-MCBS long term benefit criteria when evaluated with subsequently reported OS results instead of PFS (Table 3). Both trials were first evaluated using PFS due to immature OS results and met the criteria of long term PFS benefit with $>10 \%$ improvement. When undated mature OS results were available, they were reevaluated using OS and did not meet the criteria of long term OS benefit that OS advantage continues to be observed at 7 years.

By the ASCO-VF, the NHB were changed for 13 trials with updated results (Fig. 2, Table 3). One indication, durvalumab as consolidation therapy for stage III NSCL C, obtained a NHB of 47.7 with initial PFS results [15] but obtained an updated NHB of 41.8 based on the OS results [16]. For the rest of 13 trials, the NHB based on the updated reports is improved because of the awarding of bonus points for a statistically significant improvement in the QoL (7 trials) or/and statistically significant improvement in cancer-related symptoms (7 trials) and/ or statistically significant improvement in treatment-free interval (1 trial). The median improvement of NHB was 10 (range 2-20). The maximum 20 increase of NHB were seen in three indications: pembrolizumab as second line therapy for advanced urothelial carcinoma (KETNOTE-045 trial) [17, 18], pembrolizumab as first-line NSCLC with tumors express PD-L1 $>50 \%$ as determined by an FDA-approved test (KETNOTE-024 trial) [19, 20], and nivolumab as second line therapy of advanced nonsquamous NSCLC (CHECKMATE-057 trial) [21, 22].

\section{Discussion}

A previous study by Vivot A et al. [7], which assessed the clinical benefit of new drugs for treating advanced solid tumors aproved by the US FDA between 2000 and 2015 using ASCO-VF and ESMO-MCBS, reported that $13(35 \%)$ out of 51 approved anticancer drugs showed a meaningful clinical benefit (scale levels 4 and 5) by
ESMO-MCBS, and the median drug value was 37 (interquartile range 3.4-67) by ASCO-VF. Another study by Tibau A et al. [5] evaluated the magnitude of clinical benefit of cancer drugs approved by the US FDA from January 2006 to December 2016 using ESMO-MCBS, and found that fewer than half of RCTs supporting FDA approval meet the threshold for clinically meaningful benefit. However, less than $20 \%$ of the approved agents were immune checkpoint inhibitors in these studies, with more than $60 \%$ of approved agents being target therapy.

In our analysis, all trials met the ESMO-MCBS meaningful benefit threshold and by the ASCO-VF, the median NHB of drugs was 55.3 (range 17.4-77.1). Although caution should be taken in interpreting across study comparisons, due to the fact we used updated ASCO-VF and ESMO-MCBS, the clinical benefit seems greater in immune checkpoint inhibitors than other approved cancer drugs. Only two trials in the adjuvant setting were included in our study. Both trial meet the ESMO-MCBS 1.1 threshold for meaningful benefit. NHB of the two agents were 37.8 and 17.4, which seems lower than those in the metastatic setting. Further studies are need to evaluate whether the clinical benefit of immune checkpoint inhibitors in the adjuvant setting is consistent with those in the metastatic setting with more agents were approved in the adjuvant setting.

Recently, Ben-Aharon et al. [23], tried to determine whether immuno-oncology agents approved by the FDA fulfill the durable survival threshold defined in the updated ASCO-VF. They found only 3 drug indications fulfilled the threshold. However, in our study, 12 of 18 approved indications gained the bonus points for durable survival benefits. Several issues may explain the discrepancies. First,, as pointed by Vivot et al. in their letter [24] to the editor and Schnipper et al. in their commentary [25], Ben-Aharon et al. used raw proportions of patients at risk (ie, number of patients still at risk divided by the number of patients randomized) to estimate the survival proportion instead of using the probability displayed on Kaplan-Meier curves, which may have may have disqualify trials that actually met the ASCO-VF criteria for long term benefit.. Second, only 10 indications approved based on RCTs were eligible for their analysis. Only recently more RCTs of immunotherapy have been finished and reported. And they were never evaluated with ESMO-MCBS. Our study provided important and comprehensive evaluation of approved immune checkpoint inhibitors in RCTs.

Although our study did not aim to or was powered to assess the consistency of updated ASCO-VF and the ESMO-MCBS 1.1 due to limited number of RCTs included, Clinical benefits by updated ASCO-VF and the ESMO-MCBS 1.1 yielded some sorts of consistencies. 


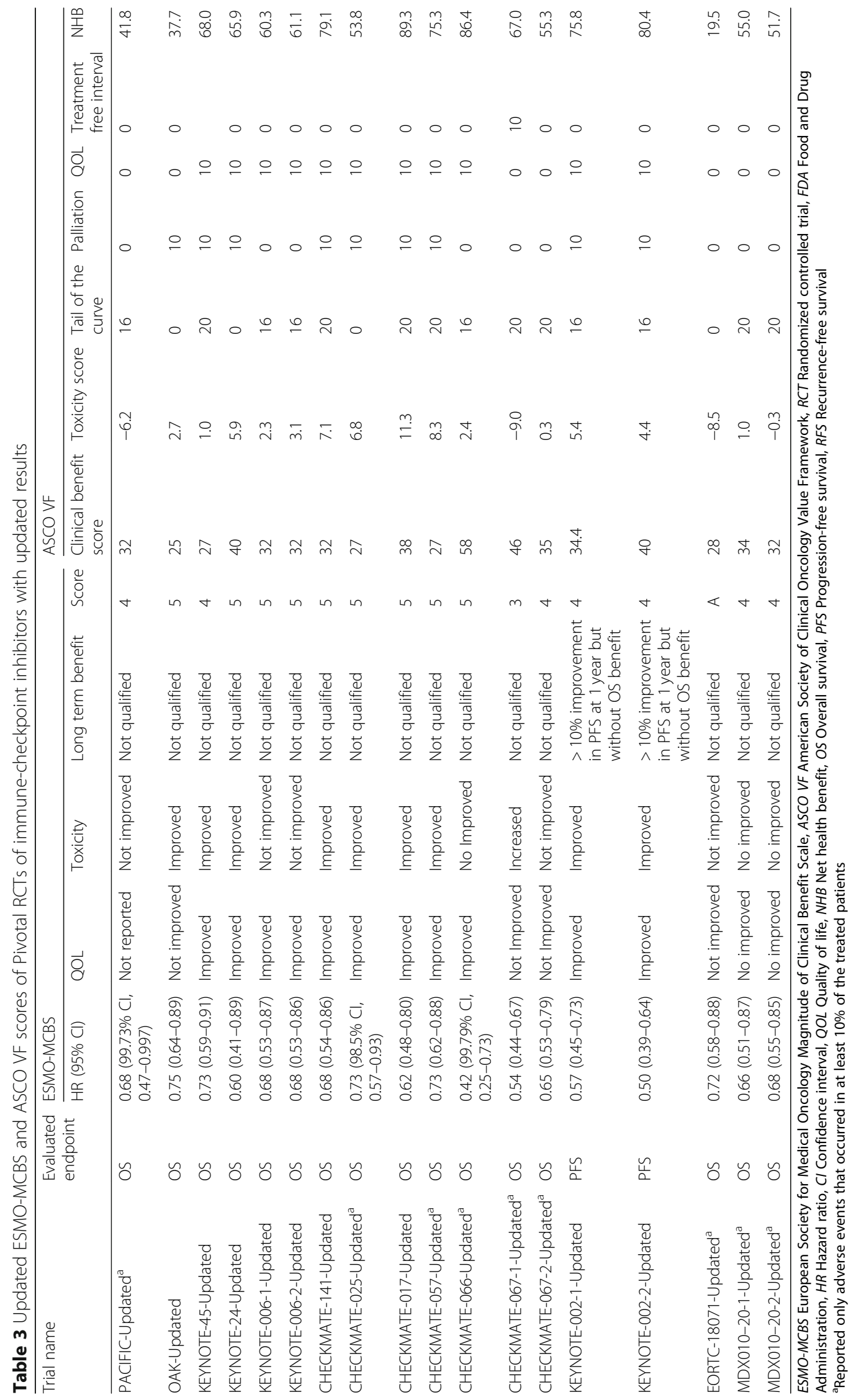




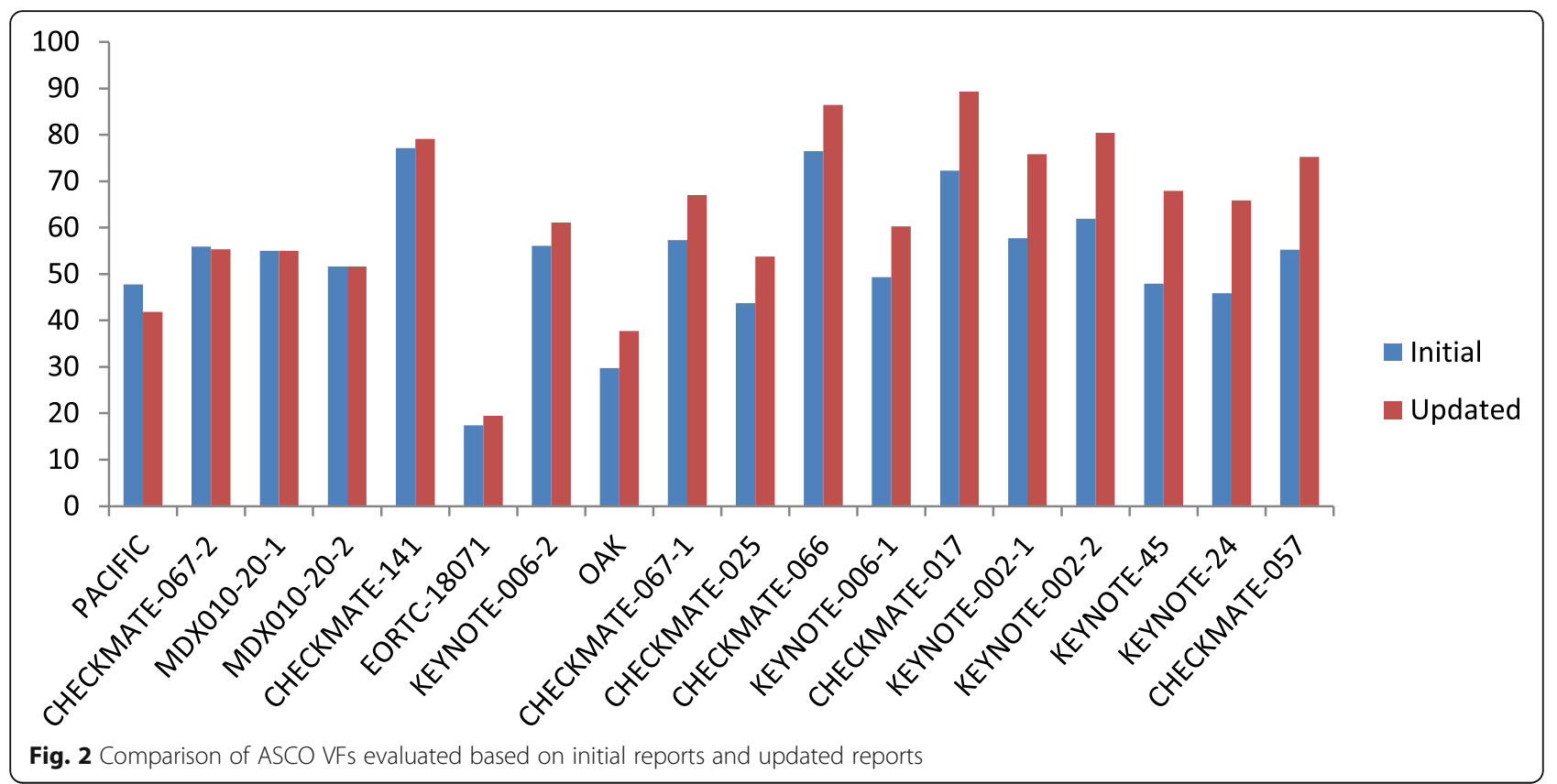

For trials with ESMO-MCBS grade of 5 or A, the median NHB was numerical higher than those with ESMO-MCBS grade of 4. A recent study [26] that evaluated the concordance between the two frameworks in the noncurative setting showed that agreement between the frameworks was higher than observed in other studies that sought to compare them $[27,28]$. This study was done by the authorship group of the two frameworks (vs independent groups). Concordance will likely be greater when those individuals who created the value frameworks are the ones scoring/ grading. Another cohort comparing the two frameworks has also drawn similar conclusions [29]. The issue of framework utility in the general oncology community has been raised recently [30].

We found that 12 of 18 indications gained the bonus points for tails of the curve, while only 3 indications met the ESMO-MCBS long term benefit criteria, all with the primary endpoint of PFS. This discrepancy is not surprising given the differences in their criteria. To qualify for the long-term plateau by ESMO-MCBS 1.1 [4], overall survival advantage need to be observed at 5 years if the median overall survival in the standard arm $\leq 12$ months. Currently none of these trials in the noncurative setting reported survival results at 5 years.

When updated results were incorporated in the assessment, clinical benefit of most approved immune checkpoint inhibitors increased, largely due to the statistically significant improvement in the QoL or/and cancerrelated symptoms that were not available in the primary reports but reported subsequently. Thus, the score may change when data mature. Our results emphasized the importance of PROs in accurately evaluating the clinical benefit of immune checkpoint inhibitors.

Our study has several limitations. First, toxicities information were extracted from published articles, which often reported only adverse events that occurred in at least $10 \%$ of the treated patients, thus, the toxicity grade by ASCO VF may change with complete toxicity information. Second, although we conducted comprehensive research, PROs reports were not available for all approved agents, clinical benefit of these agents may change when PROs report were available. Third, we focused on clinical benefit of immune checkpoint inhibitors, and no comparisons to approved chemotherapy or other agents over a similar time period were conducted.

\section{Conclusion}

In summary, all of the approved immune checkpoint inhibitors based on RCTs meet the ESMO-MCBS threshold for clinical benefit, and two thirds of these approved agents fulfilled the durable benefit thresholds in the updated ASCO VF. This information may be used in future analysis to better define clinical benefits of immunotherapies.

\section{Abbreviations}

ESMO-MCBS: European Society for Medical Oncology Magnitude of Clinical Benefit Scale; ASCO-VF: American Society of Clinical Oncology (ASCO) Value Framework; PROs: Patient-reported outcomes; QOL: Quality of life

\section{Acknowledgements}

We thank Dr. Ian Tannock, Princess Margaret Cancer Centre and University of Toronto, for his assistance in reading and editing the manuscript. 


\section{Authors' contributions}

Conceptual Design: S. Z and F.L. Drafting of the Article: S. Z and F. L Statistical Analysis: S. Z and F. L Acquisition of data: S. Z, F. L, Q. W, and W.L. Final Approval of the Article: S. Z, F. L, Q. W,and W.L. All authors have read and approved the manuscript.

\section{Funding}

None.

\section{Availability of data and materials}

All relevant data have been provided in the text and on-line supplement. Data sharing: Data extracted from published manuscript is available from the senior author at wozhangsheng@hotmail.com.

\section{Ethics approval and consent to participate}

Ethics approval was not required for this study because it was based on publicly available data and involved no individual patient data collection or analysis.

\section{Consent for publication}

Consent for publication is not needed as no individual patient data or images are involved in this research.

\section{Competing interests}

For Sheng Zhang: None

For Fei Liang: None

For Qin Wang: None

For Wenfeng Li: None

\section{Author details}

'Medical Oncology, Shanghai Cancer Center, Fudan University, 270 Dongan Road, Shanghai 200032, China. ${ }^{2}$ Department of Biostatistics, Zhongshan Hospital, Fudan University, Shanghai, China. ${ }^{3}$ Shanghai University of Engineering Science, Shanghai, China. ${ }^{4}$ Department of Medical oncology, the affiliated hospital of Qingdao University, Qingdao, China.

Received: 13 May 2019 Accepted: 18 August 2020

Published online: 31 August 2020

\section{References}

1. Schnipper LE, Davidson NE, Wollins DS, Tyne C, Blayney DW, Blum D, Dicker AP, Ganz PA, Hoverman JR, Langdon R, et al. American Society of Clinical Oncology statement: a conceptual framework to assess the value of Cancer treatment options. J Clin Oncol. 2015;33(23):2563-77.

2. Schnipper LE, Davidson NE, Wollins DS, Blayney DW, Dicker AP, Ganz PA, Hoverman JR, Langdon R, Lyman GH, Meropol NJ, et al. Updating the American Society of Clinical Oncology value framework: revisions and reflections in response to comments received. J Clin Oncol. 2016;34(24): 2925-34.

3. Cherny NI, Sullivan R, Dafni U, Kerst JM, Sobrero A, Zielinski C, de Vries EG, Piccart MJ. A standardised, generic, validated approach to stratify the magnitude of clinical benefit that can be anticipated from anti-cancer therapies: the European Society for Medical Oncology magnitude of clinical benefit scale (ESMO-MCBS). Ann Oncol. 2015;26(8):1547-73.

4. Cherny NI, Dafni U, Bogaerts J, Latino NJ, Pentheroudakis G, Douillard JY, Tabernero J, Zielinski C, Piccart MJ, de Vries EGE. ESMO-magnitude of clinical benefit scale version 1.1. Ann Oncol. 2017;28(10):2340-66.

5. Tibau A, Molto C, Ocana A, Templeton AJ, Del Carpio LP, Del Paggio JC, Barnadas A, Booth CM, Amir E. Magnitude of clinical benefit of Cancer drugs approved by the US Food and Drug Administration. J Natl Cancer Inst. 2018;110(5):486-92.

6. Grossmann N, Del Paggio JC, Wolf S, Sullivan R, Booth CM, Rosian K, Emprechtinger R, Wild C. Five years of EMA-approved systemic cancer therapies for solid tumours-a comparison of two thresholds for meaningful clinical benefit. Eur J Cancer. 2017:82:66-71.

7. Vivot A, Jacot J, Zeitoun JD, Ravaud P, Crequit P, Porcher R. Clinical benefit, price and approval characteristics of FDA-approved new drugs for treating advanced solid cancer, 2000-2015. Ann Oncol. 2017;28(5):1111-6.

8. Secord AA, Coleman RL, Havrilesky LJ, Abernethy AP, Samsa GP, Cella D. Patient-reported outcomes as end points and outcome indicators in solid tumours. Nat Rev Clin Oncol. 2015;12(6):358-70.
9. Di Maio M, Basch E, Bryce J, Perrone F. Patient-reported outcomes in the evaluation of toxicity of anticancer treatments. Nat Rev Clin Oncol. 2016; 13(5):319-25.

10. FDA. Breakthrough therapy at FDA. https://www.fda.gov/Drugs/ DevelopmentApprovalProcess/HowDrugsareDevelopedandApproved/ DrugandBiologicApprovalReports/NDAandBLAApprovalReports/ucm373418. htm. Accessed 20 May 2018

11. Robert C, Long GV, Brady B, Dutriaux C, Maio M, Mortier L, Hassel JC, Rutkowski P, McNeil C, Kalinka-Warzocha E, et al. Nivolumab in previously untreated melanoma without BRAF mutation. N Engl J Med. 2015;372(4):320-30.

12. Long GV, Atkinson V, Ascierto PA, Robert C, Hassel JC, Rutkowski P, Savage KJ, Taylor F, Coon C, Gilloteau I, et al. Effect of nivolumab on health-related quality of life in patients with treatment-naive advanced melanoma: results from the phase III CheckMate 066 study. Ann Oncol. 2016;27(10):1940-6.

13. Ferris RL, Blumenschein G Jr, Fayette J, Guigay J, Colevas AD, Licitra L, Harrington K, Kasper S, Vokes EE, Even C, et al. Nivolumab for recurrent squamous-cell carcinoma of the head and neck. N Engl J Med. 2016;375(19): 1856-67.

14. Ferris RL, Blumenschein G Jr, Fayette J, Guigay J, Colevas AD, Licitra L, Harrington KJ, Kasper S, Vokes EE, Even C, et al. Nivolumab vs investigator's choice in recurrent or metastatic squamous cell carcinoma of the head and neck: 2-year long-term survival update of CheckMate 141 with analyses by tumor PD-L1 expression. Oral Oncol. 2018;81:45-51.

15. Antonia SJ, Villegas A, Daniel D, Vicente D, Murakami S, Hui R, Yokoi T, Chiappori A, Lee KH, de Wit M, et al. Durvalumab after Chemoradiotherapy in stage III non-small-cell lung Cancer. N Engl J Med. 2017;377(20):1919-29.

16. Antonia SJ, Villegas A, Daniel D, Vicente D, Murakami S, Hui R, Kurata T, Chiappori A, Lee KH, de Wit M, et al. Overall survival with Durvalumab after Chemoradiotherapy in stage III NSCLC. N Engl J Med. 2018;379(24):2342-50.

17. Bellmunt J, de Wit R, Vaughn DJ, Fradet Y, Lee JL, Fong L, Vogelzang NJ, Climent MA, Petrylak DP, Choueiri TK, et al. Pembrolizumab as second-line therapy for advanced Urothelial carcinoma. N Engl J Med. 2017;376(11): 1015-26.

18. Vaughn DJ, Bellmunt J, Fradet Y, Lee JL, Fong L, Vogelzang NJ, Climent MA, Petrylak DP, Choueiri TK, Necchi A, et al. Health-related quality-of-life analysis from KEYNOTE-045: a phase III study of Pembrolizumab versus chemotherapy for previously treated advanced Urothelial Cancer. J Clin Oncol. 2018:36(16):1579-87.

19. Reck M, Rodriguez-Abreu D, Robinson AG, Hui R, Csoszi T, Fulop A, Gottfried M, Peled N, Tafreshi A, Cuffe S, et al. Pembrolizumab versus chemotherapy for PD-L1-positive non-small-cell lung Cancer. N Engl J Med. 2016;375(19): 1823-33.

20. Brahmer JR, Rodriguez-Abreu D, Robinson AG, Hui R, Csoszi T, Fulop A, Gottfried M, Peled N, Tafreshi A, Cuffe S, et al. Health-related quality-of-life results for pembrolizumab versus chemotherapy in advanced, PD-L1positive NSCLC (KEYNOTE-024): a multicentre, international, randomised, open-label phase 3 trial. Lancet Oncol. 2017;18(12):1600-9.

21. Borghaei H, Paz-Ares L, Horn L, Spigel DR, Steins M, Ready NE, Chow LQ, Vokes EE, Felip E, Holgado E, et al. Nivolumab versus Docetaxel in advanced nonsquamous non-small-cell lung Cancer. N Engl J Med. 2015;373(17):1627-39.

22. Reck M, Brahmer J, Bennett B, Taylor F, Penrod JR, DeRosa M, Dastani H, Spigel DR, Gralla RJ. Evaluation of health-related quality of life and symptoms in patients with advanced non-squamous non-small cell lung cancer treated with nivolumab or docetaxel in CheckMate 057. Eur J Cancer. 2018;102:23-30.

23. Ben-Aharon O, Magnezi R, Leshno M, Goldstein DA. Association of Immunotherapy with Durable Survival as defined by value frameworks for Cancer care. JAMA Oncol. 2018;4(3):326-32.

24. Vivot A, Crequit P, Porcher R. Improving on tail-of-the-curve evaluation with the American Society of Clinical Oncology value framework. JAMA Oncol. 2018:4(10):1437-8.

25. Schnipper LE, Schilsky RL. Are value frameworks missing the mark when considering Long-term benefits from Immuno-oncology drugs? JAMA Oncol. 2018;4(3):333-4

26. Cherny NI, EGEd V, Dafni U, Garrett-Mayer E, SE MK, Piccart M, Latino NJ, Douillard J-Y, Schnipper LE, Somerfield MR, et al. Comparative assessment of clinical benefit using the ESMO-magnitude of clinical benefit scale version 1. 1 and the ASCO value framework net health benefit score. J Clin Oncol. 2019;37(4):336-49.

27. Cheng S, McDonald EJ, Cheung MC, Arciero VS, Qureshi M, Jiang D, Ezeife D, Sabharwal M, Chambers A, Han D, et al. Do the American Society of 
Clinical Oncology value framework and the European Society of Medical Oncology Magnitude of clinical benefit scale measure the same construct of clinical benefit? J Clin Oncol. 2017;35(24):2764-71.

28. Del Paggio JC, Sullivan R, Schrag D, Hopman WM, Azariah B, Pramesh CS, Tannock IF, Booth CM. Delivery of meaningful cancer care: a retrospective cohort study assessing cost and benefit with the ASCO and ESMO frameworks. Lancet Oncol. 2017;18(7):887-94.

29. Becker DJ, Lin D, Lee S, Levy BP, Makarov DV, Gold HT, Sherman S. Exploration of the ASCO and ESMO value frameworks for antineoplastic drugs. J Oncol Pract. 2017;13(7):e653-65.

30. Del Paggio JC, Cheng S, Booth CM, Cheung MC, Chan KKW. Reliability of oncology value framework outputs: concordance between independent research groups. JNCI Cancer Spectr. 2018;2(3):pky050.

\section{Publisher's Note}

Springer Nature remains neutral with regard to jurisdictional claims in published maps and institutional affiliations.

Ready to submit your research? Choose BMC and benefit from:

- fast, convenient online submission

- thorough peer review by experienced researchers in your field

- rapid publication on acceptance

- support for research data, including large and complex data types

- gold Open Access which fosters wider collaboration and increased citations

- maximum visibility for your research: over $100 \mathrm{M}$ website views per year

At $\mathrm{BMC}$, research is always in progress.

Learn more biomedcentral.com/submissions 